\title{
RESPONDING TO GENDER BASED VIOLENCE ALONG MIGRATION ROUTES TO EUROPE: CASE OF MACEDONIA ${ }^{34}$
}

\author{
Stojanka Mirceva, PhD \\ Faculty of Security-Skopje, University St. Kliment Ohridski, Bitola \\ E-mail: s.mirceva@gmail.com \\ Rade Rajkovchevski, PhD \\ Faculty of Security-Skopje, University St. Kliment Ohridski, Bitola \\ E-mail: raderaj@yahoo.com
}

\begin{abstract}
There is a growing consent that vulnerability to gender based violence (hereinafter, GBV) increases during forced mass movement of people, and that refugee women and girls are particularly affected. The paper aims to provide an insight and to unpack the complex question of how do we respond to gender based violence affecting people travelling along migration routes to Europe. Worth noting is the fact that there are scarce data, if any, on national response to GBV en route to Europe. The analyses presented is based on the findings from a small-scale survey initiated by MARRI Regional Centre "Challenges in the identification and the protection of vulnerable individuals and victims of gender based violence and trafficking in human beings in the context of the current migration crisis", conducted in 3 MARRI participants in the summer, 2017.

The paper examines practices and policies in relation to responding to GBV only in the Republic of Macedonia. The analysis is based on qualitative data collected using interviews and document analysis. Sources of data in Macedonia were governmental professionals and CSO field workers who acted as first line respondents in the mixed migration flow. Data collection was conducted in the period June-July 2017.

All findings relate only to the respondents' understanding and recognition of GBV and provide initial insight on responding to GBV affecting people travelling along Balkan route to Europe. Thus, findings have no purpose to present "objective" reality of the operation of the system of identification and protection from GBV.
\end{abstract}

Key words: Gender based violence, Balkan route, recognition, identification.

\footnotetext{
34 The paper was presented at the International conference, MIGRATION AND REFUGEES IN A GLOBALIZED WORLD: RESPONSIBILITIES AND RESPONSES, 5-7 September 2018, Ohrid, Macedonia, organized by University "Ss. Cyril and Methodius", Faculty of Philosophy - Skopje, Institute for Security, Defence and Peace Studies.
} 


\section{Introduction}

In recent years, the European continent has been witnessing mass flows of refugees and migrants dominantly from Syria, Iraq and Afghanistan. Situated at the center of the Balkan route and bordering EU countries, Republic of Macedonia is largely considered as a main transit country on the route from Greece towards other EU countries.

There is a growing recognition of association of gender based violence with population on the move. Many reports of international and humanitarian organizations concerned with mixed migration flows via Western Balkan Route observed that gender based violence is widespread and is particularly affecting women and children travelling the routes (UNHCR, UNFPA, WRC,2016; UN Women, 2016; IOM, 2016). These concerns are particularly relevant in light of responding to, and protection against GBV. In order to unpack the complex question of how we respond to gender based violence affecting people travelling en route to Europe, it is necessary to address the meaning and understanding of GBV.

The term GBV was initially used in the Declaration on the Elimination of Violence against Women (DEVAW, 1993), describing violence against women as "any act of gender-based violence". Hence, the term GBV become a synonym for violence against women. An explanation of the scope of the term was provided by the Committee on the Elimination of Discrimination against Women (CEDAW) in General recommendation No. 19, and recently in Article 3 of the Council of Europe Convention on preventing and combating violence against women and domestic violence (Istanbul Convention), as follows, "Gender-based violence is violence that is directed against a woman because she is a woman or that affects women disproportionately". The latest clarification is provided with CEDAW GR No. 35 on gender-based violence against women, updating general recommendation No. 19. It is more precise and uses the term 'gender-based violence against women'. Such an expression has a twofold effect in clarifying the meaning of GBV against women, and explicitly underlines the gendered causes and impact of the violence. "This expression further strengthens the understanding of this violence as a social - rather than an individual problem, requiring comprehensive responses, beyond specific events, individual perpetrators and victims/survivors (CEDAW GR 35)".

In the last decades there has been a growing illumination of the presence of GBV against women and girls. According to a WHO study, GBV against women is one of the most widespread violations of human rights, with $25,4 \%$ of women in Europe and Central Asia who have experienced physical or sexual violence by an intimate partner or sexual violence by a non-partner (WHO et al 2013).

There is an ongoing debate on what GBV is in the pursuit of an all-encompassing response to GBV in a humanitarian context. As noted by Read-Hamilton (2014), there has been a shift in the response to GBV in humanitarian settings. Namely, initially, responding to GBV has been identified as a synonym to responding to violence against women, which had been 'hard-won battle' in recognizing the vulnerability and harms to women and girls. In particular, the violence against women and girls in 1990's in humanitarian emergencies (Former Yugoslavia, Rwanda). 
This approach is grounded in feminist practice and encompasses empowerment and prioritization of women's needs and is survivors-centered.

However, there are loud calls for broadening the understanding of GBV in conflict and post-conflict settings that originated from the growing awareness of 'gendered and sexualized' (ibid, 2014) violence in conflict also against men and LGBTI people. The gender roles assigned to men and women in society shape the causes, effects and dynamics of violence perpetrated against women. Namely, due to their prescribed gender roles violence against women is perpetrated to punish and humiliate them, while sexual and gender based violence against men is mostly intended to emasculate them and to undermine their role in the community. Nonetheless, the same response to women and men survivors of 'gendered and sexualized violence' in conflict by simply adding men and boy's survivors to developed policies for addressing violence against women proved unproductive. Defining GBV "using the definition of violence against women from the DEVAW, with men and boys added. ....... describing different forms of violence against men, such as trafficking, as gender-based by using the definition of violence against women....is problematic (Ibid, 2014:2)."

The Inter-Agency Standing Committee defines GBV as "an umbrella term for any harmful act that is perpetrated against a person's will and that is based on socially ascribed (i.e. gender) differences between males and females. It includes acts that inflict physical, sexual or mental harm or suffering, threats of such acts, coercion, and other deprivations of liberty. These acts can occur in public or in private (IASC, 2015:5)". It is obvious that the definition is not restricted only to women and girls, since it uses the term 'person'. While acknowledging that GBV is mainly perpetrated by men and the victims are mainly women, the term allows that men and boys can also be victims (of men or women), and women can be perpetrators. Hence, as pointed out by Russo and Pirlott, "Gender shapes the meaning of violent acts differently for women and men, .... and that meaning varies widely depending on the situational and cultural context (2006:179)". GBV has different impact toward women and men and highly depends on the structural, cultural and situational context of the gender. However, the Guidelines acknowledge the need for protection of all population affected by humanitarian crises and at the same time recognize "the heightened vulnerability of women and girls to GBV and provide targeted guidance to address these vulnerabilities (ibid, 2015:6)."

The notion of gender as a social and cultural construct assigned to females as opposite to males based on biological sex can vary and change within the culture and over time. In this context, it is important to acknowledge that gender is a complex category encompassing roles, values, expectations, norms, traits, behavior, environment and relationship that go beyond sex differences in determining female or male or "personal attributes of the individual"(ibid, 2006:180).

The paper focuses on discussions around understanding and recognition of GBV, in particular the perception of various types of GBV among professionals from governmental institutions (GI) and civil society organizations (CSO). In particular, to identify the challenges in the identification and protection against GBV that shape the response to such situations in a gender-sensitive way. The paper aims to provide an insight and to unpack the complex question of how do we respond to gender based violence affecting people travelling along migration routes to Europe. 


\section{Security}

Worth noting is that there are scarce data, if any, on national responses to GBV en route to Europe. The analysis presented is based on the findings from a small scale survey ${ }^{35}$ conducted in 3 MARRI participants in the summer, 2017. This paper examines practices and policies in relation to GBV response only in the Republic of Macedonia.

Apart from the introductory notes, the paper is structured in two sections. The first section elaborates the national context during mass flows of people on the move on their route to Europe. In particular, an overview of laws, practices and standards in relation to identification and protection against GBV is presented since the main assumption is that the relevant stakeholders operate within the national legal and organizational framework. Before discussing the findings, the second section provides information on methods used for data gathering and data sources. Key themes identified in relation to responding to GBV are explored: understanding of $\mathrm{GBV}$, the types of GBV, and the meaning of gender in participants' professional conduct. Due attention is also given to the limitations of the survey. In the concluding remarks the paper opens further debate on the necessity not only to set up an unambiguous legislation on GBV and clear procedures, but also for developing gender-sensitive understanding of violence against women in provision of support services.

\section{National context}

The term GBV emerged in the last decade in the Republic of Macedonia mainly to refer to domestic violence. However, there is no clarification on national level what does GBV means, rather there is a confusion in terms of nature, types and root causes. Scarce debates rooted in feminist theory were mainly initiated by women's civil society organizations supported by UN bodies. The starting point is the DEVAW, 1993, which provisions underline the structural nature of violence against women committed by men. This framework highlights that GBV is both, a cause and a consequence of women's inequality. It is linked to understanding of gender based violence as women's human rights violation and discrimination. Thus, the term "gender based violence" is used as a synonym for violence against women and girls. It recognizes male domination and female subordination as a result of oppressive social arrangements. GBV is embedded in unequal power relationships between men and women. This violence does not affect women randomly, rather it is directed against women because they are women (Kelly 2005). These international documents emphasized that violence against women is gender-based.

35 The publication "Assessment Report: Challenges in the identification and the protection of vulnerable individuals and victims of gender based violence and trafficking in human beings in the context of the current migration crisis", is produced with the support of MARRI Regional Centre - Migration, Asylum, Refugee, Regional Initiative in cooperation with Catholic Relief Services in 2017. The study was initiated by MARRI Regional Centre in order to contribute to the development and adoption of regionally harmonized approach among MARRI Participants in identification and protection of vulnerable individuals and victims/survivors of gender-based violence and/or trafficking in human beings in the mixed migration flow. 
As a member state of the United Nations and the Council of Europe, the Republic of Macedonia ratified the most important international instruments regarding human rights and freedoms by way of succession (Official Gazette of the Republic of Macedonia, No. 57/1993). The Republic of Macedonia is a party to the International Covenant on Social, Economic and Cultural Rights; the International Covenant on Civil and Political Rights; 1951 Refugee Convention and to the 1967 Protocol, the Convention relating to the Status of Stateless Persons, the Convention on Organized Crime and its Protocols, the Convention on the Elimination of All Forms of Discrimination against Women (CEDAW) and the Optional Protocol; the Convention on Action against Trafficking in Human Beings, the Convention on the Rights of the Child (CRC) and the two Optional Protocols; and the Council of Europe Convention for the Protection of Human Rights and Fundamental Freedoms, Revised European Social Charter, as well as other international documents. An international instrument that is a major step forward in preventing and combating gender based violence, the Council of Europe Convention on preventing and combating violence against women and domestic violence (Istanbul Convention) in the Republic of Macedonia entered into force on July, $1^{\text {st }}, 2018$. As of July, $8^{\text {th }}, 2011$, Macedonia was only a signatory to the Convention, and at the time of conducting the survey the Convention was not ratified.

In the national legislation, the phenomenon of violence against women (VAW) is not specifically addressed, although it has long history and tradition. It is vastly marginalized and consequently, there is no legislative document that comprehensively addresses VAW. The current national legal framework, in relation to VAW dominantly addresses family violence, trafficking in human beings and child sexual abuse. For the first time in 2004, some forms of GBV were specifically addressed with the legal regulation and sanctioning of family violence. Therefore, most policies and strategies focused on family violence and left other forms of VAW legally unregulated.

Gender based violence against women remains a huge challenge in the country in terms of policy level and legal recognition for comprehensively addressing all forms of VAW tied to the positioning violence against women in the gender power relations, and as a form of discrimination against women (Mirceva, Caceva, Kenig, 2014, Brankovic \&Mirceva, 2018). Moreover, obscure legal regulation and lack of political will to address GBV in its full scope are not the only barriers in the process of developing adequate responses to VAW. Value system represents a serious challenge to addressing gender based violence against women.

The practice of promoting traditional patriarchal values and gender roles was already annotated in CEDAW reports, whereas the Committee expresses its concern about "the persistence of patriarchal attitudes and deep-rooted stereotypes regarding the roles and responsibilities of women and men in the family and society. These stereotypes present a significant impediment to the implementation of the Convention and are a root cause of the disadvantaged position of women in a number of areas ..."Furthermore, the Committee " urges the State party to give priority to putting in place comprehensive measures to address all forms of violence against women, including domestic violence, recognizing that such violence is a form of discrimination and constitutes a violation of women's human rights under the Convention....( CEDAW/C/MKD/CO/3,Para.118)". 
The only national legal definition of GBV against women was introduced with the Law on Prevention and Protection against Domestic Violence (Official Gazette of the Republic of Macedonia, No. 138/2014), as follows, "GBV against women is violence directed against women because they are women or that affect them disproportionately" (Art.4). Still, such definition needs to be read within the scope of this Law, namely, prevention and protection against domestic violence.

Within such legal framework, the only standards for responding to GBV were contained in the Inter-agency Standard Operating Procedure (SOP) for prevention and response to GBV in emergencies. During 2015-2016 the country faced an exceptional situation with unprecedented numbers of people on the move and transiting through the country using the Balkan Route to reach EU countries. According to UNHCR estimates, 697,228 refugees and migrants have entered at Gevgelija and transited through the country as of 1 July, 2015 till 8 March 2016 (UNHCR,2016), which is equivalent of more than a third of the population of the country. The Government of the Republic of Macedonia adopted an SOP for prevention and response to GBV in emergencies on 17th of February, 2017 as Annex 13 to the Plan for readiness and Health System response in dealing with emergencies and catastrophes. The ratio behind enacting such procedures was to define the roles and obligations of all stakeholders involved in responses to GBV in the Transit centers established by the Government or on other locations where people on the move may be located. At the time when these procedures were adopted, they were particularly significant for a number of reasons. Most importantly, they reflected the recognition that GBV is a widespread phenomenon, which inevitably requires an effective response to GBV. Although, the first adopted procedures to address GBV relate to emergencies, their importance is unquestionable.

However, the implementation of the SOP poses a great challenge in a context where historically the notion of GBV has not been rooted in the legal tradition nor was it recognized in the operation of the national systems for provision of support services to survivors of GBV. The reason for it is simply that those who are expected to implement the SOP have no experience in gendered understanding and responding to GBV in their everyday work. Furthermore, the SOP has ambitious goal to pose a legal obligation to all sectors that might be involved in prevention, identification and response to GBV, and not only in emergencies, but also in a situation of peace. Such goal is challenging since the SOP is an annex to the Health System readiness plan. This means that other sectors operate under specific sector plans for dealing with emergencies. On the other hand, the visibility of this document for other sectors to which it introduces obligations is debatable. Apart from those technical issues, and even if they are neglected, the most important question will involve defining GBV. In the aforementioned national context, the definition of GBV is a starting point for identifying the various forms of GBV. The SOP uses the following definition, "GBV refers to protection against life threats, health and human rights that can have a destructive impact especially on women and children, as well as families and society. Violence against women means any act of gender based violence that results in, or is likely to result in, physical, sexual, or psychological harm or suffering to women, including threats of such acts, coercion or arbi- 
trary deprivation of liberty, whether occurring in public or private life. ${ }^{136}$ (SOP, para.6.1, p.10). It is obvious that such definition seriously lacks key elements of GBV, namely, understanding that gender roles and power asymmetry between man and women in society and particularly the patriarchal values that perpetuate the subordination of women are root causes. Adding the DEVAW definition of violence against women is useful, but does not clarify the term GBV.

Due to the word limits, other provisions of SOP are not further analyzed. Presenting the definition of GBV from the SOP is highly important since it is the first procedure that introduces obligations to stakeholders in the responses to GBV. But also, it represents a basis for developing understanding or misunderstanding of GBV among relevant stakeholders.

\section{Notes on Methodology}

The paper examines practices and policies in relation to responding to GBV only in the Republic of Macedonia. The analysis is based on qualitative data collected using only interviews. Sources of data were statements of interviewees given in a face-to-face interview. The sample was made on purpose. The following criteria were employed in the selection process: first line respondents with statutory duty to fight against GBV and fieldworkers - providers of humanitarian assistance and support to people on the move at entry points and sites for transit or stay. The first line respondents - governmental professionals were selected by their managerial officers, and permission to contact field workers was obtained from CSOs. Interviewees from governmental institutions consisted of camp management professionals from visited sites and border police officers. CSO field workers were selected on sites during visits to the refugee/asylum/ migrant centers. The geographic scope tailored to the time frame for the survey determined visits only to refugee/asylum/migrant centers that were located in the north of Macedonia.

A semi-structured interview guide was designed for the purpose of the research. The research period refers to March, 8th 2016- April 30th 2017. Data collection was conducted in the period June-July 2017 (Mirceva, S., Rajkovchevski, R., 2017).

A total of 5 interviews were conducted in Macedonia, 2 of which by professionals from governmental institutions and 3 by frontline workers from CSO. All interviewees were informed of the purpose and aim of the study and were guaranteed anonymity. They agreed to participate voluntarily and also to be quoted anonymously. Interviews took place in 3 refugee/transit/migrant centers as follows: Asylum center - Vizbegovo, Migration Center - Gazi Baba and Transit center in Tabanovce.

Limitations are grouped along the insufficient time frame for conducting the survey which encompasses research design corresponding to the all-embracing defined goals of the research,

\footnotetext{
36 In Macedonian language the definition reads as follows, “РБН се однесува на заштита против закани по живот, здравје и човекови права кои може да имаат деструктивно влијание особено врз жените и децата, како и семејствата и општеството. Насилството врз жените, значи секој акт на родово базирано насилство кое резултира со, или веројатно би резултирало со, физичка, сексуална или психолошка штета или страдање, вклучувајќи и закани за такви акти, принуда или лишувања од слобода, без разлика дали се случуваат во јавниот или приватниот живот", and refers to IASC, Guidelines for Integrating Gender-Based Violence Interventions in Humanitarian Action, p. 5.
} 
together with absence of disaggregated statistical data that preclude quantitative analysis. Therefore, despite the initial design that included collection of qualitative and quantitative data, the analysis includes only qualitative data.

Worth noting is that two factors relativized the generalization: the geographical scope and the period of data collection. An important factor that needs to be considered is the small number of interviewees. Therefore, when reading the findings one must bear in mind that the primary purpose is to get initial insight on the understanding and the sensibility of the main stakeholders regarding GBV affecting people travelling along the Balkan route to Europe. The findings relate only to respondents' understanding and recognition of GBV and have no purpose to present the "objective" reality of the operation of the system of identification and protection from GBV.

\section{Discussion of findings}

The research question how do we respond to gender-based violence affecting people travelling along migration routes to Europe, involves an awareness of power asymmetry, causes of GBV and myths, as well as identification and responses which is determined with existence and knowledge of legal framework and human capacities.

The discussion of findings is grouped along the lines of perception and recognition of GBV, as well as awareness of existing national instruments for identification and response to GBV as well as training. Starting from the premise that a response is shaped by the understanding of any phenomenon, the interviewees were asked about their understanding of GBV, the types of GBV and the meaning of gender in their professional conduct (ibid, 2017).

A shared perception among interviewees is that women and children refugees/migrants are dominant victims of GBV that is perpetrated by men.
"...Most commonly, women are the dominant victims......yes, and young girls under age of 18 or generally over age of 18...." (CSO interviewee).
..."Gender-based violence, domestic violence is actually violence by man to woman." (GI inter- viewee).

The main findings pertain to the recognition that the extent of the interviewees' understanding of GBV vary from narrow, often limited to the act of domestic violence, to a much broader understanding including acts of violence committed by non-family perpetrators. Two interviewees expressed broader understanding of the meaning of GBV, as a violence that occur in both, in private and in public spaces, by members of a family/intimate partner and by strangers.

"Gender-based violence, we mostly had domestic violence. We had cases where we had complaints from women refugees... who were abused, beaten by their husbands, within their family." (CSO interviewee).

".....we have had more cases of gender-based violence, we have had harassment of women, both psychologically and physically, as well as a lot of aggressive attacks towards women and children..." So, sometimes we have had different cases regardless of, maybe he is not the husband who is violent or, I don't know, maybe other people from the camp, other groups." (CSO interviewee). 
It is worth noting that only 1 interviewee referred directly to sexual violence as a manifestation of GBV. No other forms of GBV were recognized.

...."she literally complains that she doesn't have a husband, none of them is her husband, that she has left the country from which she comes, in order to save herself from the war, so these men are her companions, she has paid to them for a certain period of time, to follow her to here, but yet in Greece they started to annoy her, abuse her sexually and attack her." (Gl interviewee,)

Besides the lack of specific recognition of various types of GBV, another striking finding is that there is no explicit recognition of gender power asymmetry as a root cause of GBV. Although the interviewees acknowledged that dominant victims of GBV are women and perpetrators are men, it was not observed that they relate GBV to the subordination of refugee women to men, rather they relate the acts of GBV to 'their culture' and traditional values of the refugees/ migrants and serves as an implicit justification for the lack of gender-sensitive response.

The next relevant question for gender-sensitive response to GBV is related to the meaning of gender or how the role of gender matters in the professional conduct of the interviewees. The analysis of the significance of gender in the context of professional conduct was situated within the overall value system and policy towards gender equality. Some of the interviewees relate the question to the sex structure of the organization they worked with and provision of services to women by women. Some of them, unhesitantly pointed out that gender is irrelevant for their work, and others stated that the law is equal for all. On the other hand, two interviewees firmly acknowledge that gender is relevant for their work. However, apart from claiming a gender-sensitive approach in the provision of services, they do not support such claims with explanations of activities that have effects on gender asymmetry of power (ibid., 2017).
..."So, the gender is, the program that it implements...and previously they were gender-sensitive, so in the context of the refugee crisis we tried to give equal treatment to all refugees, but with a particular focus on those who are identified as victims of gender-based violence, regardless of its kind, regardless if it is physical, psychological, where most often, those who were victims of the violence are not aware of that." (CSO interviewee).

The perception of the interviewees of equality, in particular gender equality at the workplace is considered an important issue for the understanding and responding in a gender-sensitive way to GBV. Reluctance to comment on this question was observed at some of the interviewees, and they provided very brief answers. Most of the interviewees referred to the sex composition of the organization, stating that there is a relatively balanced representation of both sexes and that in favor of women. The following quote is an illustration,

"...." I can say that women are dominant, 60:40,60\% are female, and 40\% are male." (Gl interviewee).

The sex structure is an important precondition, however balanced representation of both sexes does not, by itself guarantee gender equality, rather it is a first step in ensuring gender equality in full meaning. One interviewee addresses this issue in more depth, explaining the 
gender equality policy in the organization beyond balanced sex structure and connecting it to decision-making power.

"It is a fact that there are more men in our organization, but concerning to the distribution of the managerial positions....there are women in managerial positions..." (CSO interviewee).

Worth noting is that interviewees also refer to national legal documents on gender equality, as a framework for operation of their organization. They report that formally there are policies on gender equality, but they are not functional in reality. In the words of the interviewees, it has been illustrated as follows:

"..according to the Law, we should have some kind of a program, in which we will have to observe some percentage of gender representation, I really think that gender equality is respected now, I mean... women, if we observe the policy for gender equality in the staff, but in practice we do not have such a thing." (Gl interviewee).

With regards to the awareness of the existence of any rules or procedures that drive their conduct, all interviewees refer to Standard Operating Procedures (SOPs) as a referral mechanism that defines the tasks and responsibilities as well as cooperation among stakeholders for identification and referral of GBV victims in crisis and emergency situations.

"The basis of our work are the standard-operational procedures... These are procedures, , that are adopted by the Republic of Macedonia, and are a way of conducting and working with juvenile persons, unaccompanied persons, victims of trafficking... for gender-based violence." $(G \mid$ interviewee).

..."there are standard-operating procedures for trafficking in human beings, for unaccompanied minors and another vulnerable category of people related to gender-based violence." (CSO interviewee).

Worth noting in relation to legal document related to GBV are the accounts of some of the interviewees who reported that they were involved in drafting the SOPs as members of the working group established for that purpose. None of the interviewees mentioned any legal document on GBV in a non-crisis situation. It is also important to highlight the perception of interviewees in relation to the applicability and implementation of SOPs. Interviewees from governmental institutions and CSOs acknowledge challenges in the content and in the implementation of SOPs (ibid. 2017:45).

..."It's nice when you have something that you haven't had until now (SOP). But if you estimate that what is inside is not useful, it's disorganized, it's not clearly stated and it's unworkable, then you have the wrong standard-operating procedures.... would put all of this on revision again, reworking and re-processing, in order to make them applicable...Otherwise, given as they are, they are absolutely useless." (Gl interviewee).

"In my opinion, they (SOPs) are good. However, we come to the part where we need to implement them. Everything is nicely written on paper and when you read it all looks nice.... But I think we still need to work on their application. That is, those who are in first, direct contact with the 


\section{Securitity}

persons, and that's the police, most often the police is the first contact, also the border police, it they are the ones who should have the experience and should detect them..." (CSO interviewee).

In relation to GBV training, most of the interviewees, both from governmental institutions and CSO field workers report that they have received training on GBV. They also reported that the trainings were on a basic level, it was a more initial training. Also, some interviewees clearly identify that GBV trainings started during the refugee crisis. According to the accounts of the interviewees, the GBV training they received was provided by UN organizations, national and international $\mathrm{CSO}_{\mathrm{s}}$, and some of them also referred to national and foreign experts as training providers. Another important issue is that the training sessions currently offered are not supported by written training manuals that will further facilitate appropriate and effective conduct of stakeholders in response to all forms of GBV.

Worth noting is the perspective that one interviewee shared in relation to who is targeted with GBV trainings and its quality. The interviewee clearly stated that there is a lack of systematic policy on developing the sensitivity and skills of professionals working in the field with refugee/migrants for an appropriate response to all types of GBV, including gaining sufficient knowledge (ibid., 2017:46).

"However, the problem is not within us as an institution... I practically sometimes get angry when some of the institutions that do not have the basic task of dealing with such situations are called upon training. Unfortunately, those present on the field, who need to be dealt with, have nothing to do with what they should practically face on the field. And they are not being trained enough to deal with what's on the field. It is not possible (....) to be affected by this which we are talking about gender-based violence, etc., minors and trafficking in human beings and other aspects, while the Ministry of Interior, the border police are not called for training or not been involved in specialized trainings." (Gl interviewee).

In a context where traditional patriarchal values and gender roles are deeply rooted, clear standards and comprehensive definition of GBV in the national laws are a necessity. Equally important is delivery of training tailored to the specific needs for identification and protection of GBV victims.

\section{Conclusion}

There is an absence of a legal definition of gender-based violence in national laws. There is a pressing need for inclusion of the definition of VAW and gender-based violence in relevant national laws in accordance with the definitions in the Istanbul Convention, its core elements, procedures for prevention and protection of women victims of GBV based on gendered understanding of violence against women. In particular, gendered understanding of violence against women is considered a core principle of the Istanbul Convention (Art.18, para.3) that shall underpins all standards. Gendered understanding of violence against women, as noted in the Explanatory Memorandum of the Convention, means that "...services offered need to demonstrate an approach, relevant to their users, which recognizes the gendered dynamics, impact and consequences 
of these forms of violence and which operates within a gender equality and human rights framework" (para. 115).

Paradoxically, gender-based violence in a crisis situation is defined, though quite debatable, in the Standard Operative Procedures for prevention of and response to gender-based violence in crisis and catastrophes, as an Annex to the Health System Plan, adopted by the Government in 2017. A direct consequence of the lack of a legal definition and procedures for prevention and protection against GBV in the everyday operation of institutions and organizations is a very narrow understanding of GBV among professionals and filed workers, who view it mainly within the context of domestic violence.

Understanding and recognizing the phenomenon of GBV is a precondition to responding to $\mathrm{GBV}$ in a gender-sensitive manner. Within the Macedonian context, it is not a surprise that the majority of the interviewees, professionals from governmental institutions and CSO field workers have a very narrow understanding of GBV, resulting in insufficient recognition of all types of GBV and limited identification of specific risks to vulnerable individuals and refugee/migrants victims. This is related to the character of the society that continues to deeply embrace patriarchal values as its prevailing value system. .

Furthermore, a critical absence of training in the field of GBV, its core elements, understanding and providing support and protection services in a gender-sensitive manner contributes to the limited GBV expertise and identification capacities among stakeholders. Identification and referral of victims of gender-based violence remains a huge challenge. There is a need to establish systematic implementation of structured trainings based on developed and adopted curricula of gender-based violence training including the core elements of GBV, discrimination, equality between women and men in society and family, identification of prejudice and dealing with gender stereotypes, roots of GBV, types of GBV and gender-sensitive response for all professionals/humanitarian workers in the relevant institutions/organizations. These processes must be accompanied with development and implementation of specialized training for different professionals' conduct with victims of various forms of VAW, together with multi-agency cooperation training.

\section{References}

1. Council of Europe (2008). Combating violence against women: Minimum standards for support services (authors: Kelly, L. and Dubois, L.). Strasbourg: Council of Europe

2. $\mathrm{COE}$ Convention on preventing and combating violence against women and domestic violence (Istanbul Convention), CETS No.: 210.

3. Explanatory report to the Council of Europe Convention on preventing and combating violence against women and domestic violence, CETS No.: 210., https://rm.coe.in$\mathrm{t} / 16800 \mathrm{~d} 383 \mathrm{a}$

4. Ertürk, Y. (2006). Integration of the human rights of women and the gender perspective: Violence against women, The due diligence standard as a tool for the elimination of vio- 
lence against women, Report of the UN Special Rapporteur on violence against women, its causes and consequences, E/CN.4/2006/61, 20 January 2006

5. European Women's Lobby (2012) Responsibility of states in Europe regarding Violence against women EWL Report to the UN Special Rapporteur on Violence against Women, 30 October 2012. Brussels: EWL

6. International Organization for Migration (IOM). (2016). Mixed Migration Flows in the Mediterranean and Beyond: Compilation of Available Data and Information. Retrieved from http://migration.iom.int/docs/2016 Flows to Europe Overview.pdf [accessed 22 August 2017].

7. Inter-Agency Standing Committee (IASC). (2015). Guidelines for Gender-Based Violence Interventions in Humanitarian Settings. Retrieved from http://gbvguidelines.org/wp/ wp-content/uploads/2015/09/2015-IASC-Gender-based-Violence-Guidelines_lo-res.pdf [accessed 06 May 2016].

8. Institute of Public Health of Republic Of Macedonia. Multisectorski standardni operativni procedure (SOP) za prevencija I odgovor na rodovo bazirano nasilstvo (RBN) vo itni I krizni sostojbi I katastrofi. Retrieved from http://iph.mk/wp-content/uploads/2014/09/Мултисекторски-стандардни-оперативни-процедури-за-превенцијаи-одговор-на-РБН.pdf [accessed 18 April 2018]

9. Kelly, L. (2005), How violence is constitutive of women's inequality and the implications for equalities work, London: Metropolitan University.

10. Law on Prevention and Protection against Domestic Violence, Official Gazette of the Republic of Macedonia, No. 138/2014.

11. Mirceva, S. 2011, "Effects of Council of Europe CAHVIO Convention on the national prevention and protection system against types of violence covered by the Convention", UNDP Office in Skopje.

12. Mirceva, S., Caceva, V., Kenig, N. (2014), " Voice for Justice: Research Report- Assessment of court proceedings in Domestic Violence cases, with specific focus on assessing the case management from gender perspective", Institute of Sociological, Political and Juridical Research-Skopje.2014.

13. Mirceva, S., Rajkovchevski, R. (2017), Assesment Report: "Challenges in the identification and the protection of vulnerable individuals and victims of gender based violence and trafficking in human beings in the context of the current migration crisis" Available at: http://marri-rc.org.mk/wp-content/uploads/2017/11/Assessment-report.pdf

14. Mirceva, S., Brankovic, B. (2018). Priracnik za policiski sluzbenici: Obezbeduvanje rodovo-senzitivni uslugi za poddrska na licata koi pretrpele semejno nasilstvo [Manual for police officers: Providing gender-sensitive support services to survivors of domestic violence]. UN Women Programme Office-Skopje. Skopje.

15. Read-Hamilton, S. (2014). Gender-based violence: a confused and contested term. Humanitarian Exchange, 60: 5-8 (2014). Humanitarian Practice Network. Retrieved from https://odihpn.org/magazine/gender-based-violence-a-confused-and-contested-term/ [accessed 18 April 2018]

16. Russo, N.F, and Pirlott, A., Gender-Based Violence: Concept, Methods and Findings, Annals New York Academy of Sciences,1087: 178-205 (2006). NY. 
17. UN Declaration on the Elimination of Violence against Women (DEVAW), 1993. (DEVAW 1993).

18. UN Convention on the Elimination of All Forms of Discrimination against Women (CEDAW), UNGA Res. 34/180 (18 December 1979).

19. UN Comm. on the Elimination of Discrimination against Women, (CEDAW Committee) (1989). General Recommendation No. 12, U.N. Doc. A/44/38.

20. UN Comm. on the Elimination of Discrimination against Women (CEDAW Committee). (1992). General Recommendation No. 19, U.N. Doc. A/47/38.

21. UN Comm. on the Elimination of Discrimination against Women (CEDAW Committee) (2005). Views of the Committee on the Elimination of Discrimination against Women under article 7, paragraph 3, of the Optional Protocol to the Convention on the Elimination of All Forms of Discrimination against Women, Communication No.: 2/2003, Ms. A. T. v. Hungary (Views adopted on 26 January 2005, thirty-second session)

22. UN Comm. on the Elimination of Discrimination against Women (CEDAW Committee) (2017). General recommendation 35 on gender-based violence against women, updating General recommendation 19, CEDAW/C/CC/35, 14 July 2017. http://tbinternet.ohchr.org/ layouts/treatybodyexternal/Download.aspx? symbolno=CEDAW/C/ GC/35\&Lang=en

23. UN Comm. on the Elimination of Discrimination against Women (CEDAW Committee). (2006). Concluding comments of the Committee on the Elimination of Discrimination against Women: the former Yugoslav Republic of Macedonia (CEDAW/C/MKD/CO/3). New York: UN.

24. UN Comm. on Elimination of Discrimination against Women. (CEDAW Committee) (2013). Concluding comments of the Committee on Elimination of Discrimination against Women: the former Yugoslav Republic of Macedonia (CEDAW/C/MKD/CO/4-5). New York: UN.

25. UN Women. (January 2016). Gender Assessment of the Refugee and Migration Crisis in Serbia and FYR Macedonia. Europe and Central Asia Regional Office, UN WOMEN, Istanbul, Turkey. Retrieved from http://eca.unwomen.org/en/digital-library/publications/2016/01/ gender-assessment-of-the-refugee-and-migration-crisis-in-serbia-and-fyr-macedonia[accessed 22 April 2017]

26. NHCR, UNFPA, WRC (2016). Initial assessment report: Protection Risks or Women and Girls in the European Refugee and Migrant Crisis. Greece and the former Yugoslav Republic of Macedonia. Retrieved fromhttp://www.unhcr.org/protection/operations/569f8f419/initial-assessment-report-protection-risks-women-girls-european-refugee.html[accessed 22 May 2017]

27. UNHCR Bureau for Europe. (2017). Desperate Journeys: Refugees and migrants entering and crossing Europe via the Mediterranean and Western Balkans routes. Retrieved from http:// www.unhcr.org/news/updates/2017/2/58b449f54/desperate-journeys-refugees-migrants-entering-crossing-europe-via-mediterranean.html [accessed 22 August 2017]

28. WHO, London School of Hygiene and Tropical Medicine, South African Medical Research Council (2013). Global and regional estimates of violence against women: prevalence and health effects of intimate partner violence and non-partner sexual violence. 